\title{
Filter-Based Assay for Escherichia coli in Aqueous Samples Using Bacteriophage-Based Amplification
}

\section{Citation}

Derda, Ratmir, Matthew R. Lockett, Sindy K. Y. Tang, Renee C. Fuller, E. Jane Maxwell, Benjamin Breiten, Christine A. Cuddemi, Aysegul Ozdogan, and George M. Whitesides. 2013. "Filter-Based Assay for Escherichia Coli in Aqueous Samples Using Bacteriophage-Based Amplification." Analytical Chemistry 85, no. 15: 7213-7220.

\section{Published Version}

doi:10.1021/ac400961b

\section{Permanent link}

http://nrs.harvard.edu/urn-3:HUL.InstRepos:12361274

\section{Terms of Use}

This article was downloaded from Harvard University's DASH repository, and is made available under the terms and conditions applicable to Open Access Policy Articles, as set forth at http:// nrs.harvard.edu/urn-3:HUL.InstRepos:dash.current.terms-of-use\#OAP

\section{Share Your Story}

The Harvard community has made this article openly available.

Please share how this access benefits you. Submit a story.

\section{Accessibility}




\title{
Filter-Based Assay for $E$. coli in Aqueous Samples using Bacteriophage-Based Amplification
}

\author{
Matthew R. Lockett ${ }^{1}$, Renee C. Fuller ${ }^{1}$, E. Jane Maxwell ${ }^{1}$, Benjamin Breiten ${ }^{1}$, Christine C. \\ Cuddemi $^{1}$, Aysegul Ozdogan ${ }^{1}$, Ratmir Derda ${ }^{1}$, Sindy K.Y. Tang ${ }^{1}$, George M. Whitesides ${ }^{1,2 *}$
}

${ }^{1}$ Department of Chemistry and Chemical Biology, Harvard University

12 Oxford Street, Cambridge, MA 02138

${ }^{2}$ Wyss Institute of Biologically Inspired Engineering, Harvard University

60 Oxford Street, Cambridge, MA 02138

*corresponding author: gwhitesides@gmwgroup.harvard.edu 


\begin{abstract}
.
This paper describes a method to detect the presence of bacteria in aqueous samples, based on the capture of bacteria on a syringe filter, and the infection of targeted bacterial species with a bacteriophage (phage). The use of phage as a reagent provides two opportunities for signal amplification: i) the replication of phage inside a live bacterial host (1000-fold amplification for M13 phage in E. coli $\mathrm{K} 12$ ), and ii) the rapid conversion of a colorless substrate to a colored or fluorescent product by an enzyme that is co-expressed with the phage (in this demonstration $\beta$ galactosidase, which has a turnover rate of $\sim 600$ molecules/second). This method can detect a single colony-forming unit (CFU) of $E$. coli in one liter of water with an overnight culture-based assay, or 50 CFUs of E. coli in 1 liter of water (or $10 \mathrm{~mL}$ of orange juice, or $10 \mathrm{~mL}$ of skim milk) in less than four hours with a solution-based assay with visual readout. The solution-based assay does not require specialized equipment or access to a laboratory, and is more rapid than existing tests that are suitable for use at the point of access. This method could be applied to the detection of many different bacteria, in parallel, with bacteriophages that express enzymes not natively expressed in the target bacteria.
\end{abstract}




\section{Introduction.}

The guidelines for monitoring bacterial contamination in a public supply of water, or in a supply of food, are stringent to mitigate threats to public health. Analytical methods approved by the Environmental Protection Agency (EPA) must ensure that a public water supply maintains fewer than one colony-forming unit (CFU) of coliform bacteria in $100 \mathrm{~mL}$ of water, ${ }^{1}$ and the Food and Drug Administration (FDA) has a "zero tolerance" policy for the presence of bacterial species such as E. coli O157:H7, Salmonella sp., and Listeria monocytogenes in foodstuffs. ${ }^{2,3}$

The detection of such small numbers of bacteria requires an amplification step: EPAapproved methods rely on microbiological culture, affinity capture (based on antibodies), ${ }^{4,5}$ or the amplification of nucleic acids. ${ }^{3,6}$ Microbiological cultures determine the number of live bacteria in a sample, but require incubation periods ranging from several hours to several days at temperatures between $30-45^{\circ} \mathrm{C} ;{ }^{7,8}$ the "rapid" test for coliform bacteria approved by the EPA requires a 16-hour incubation at $35{ }^{\circ} \mathrm{C}$. Nucleic acid-based methods such as multiplexed PCR can determine the identity and number of bacteria present in a sample ${ }^{9,10}$ within a period of $2-8$ hours, but are more difficult and costly to run than cultures because they require access to laboratory equipment and reagents. There are a number of lab-on-chip ${ }^{11,12}$ and paper-based ${ }^{13,14}$ prototypes, but none have yet provided a simple analytical method that meets the approval of the EPA. Several commercial products are also available to detect coliform bacteria in a sample of water, at the point of access, but these products are culture-based, and require incubation periods of 12 hours or longer.

Bacteriophages (phages) are viruses that selectively infect a bacterial host, and utilize the cellular machinery of the host to replicate in number. Phages are well-suited as a reagent for detecting the presence of bacteria in a sample, because they: i) amplify in number naturally, once 
they have infected the targeted host; ii) are species- or serotype-specific, ${ }^{15,16}$ and this specificity reduces the probability of a false-positive result; iii) require a single reagent, the phage of interest; iv) can be produced in large numbers at a low cost; v) can be stored for long periods in a dry state; ${ }^{17,18}$ vi) pose no threats to humans, and can be handled without fear of infection or illness $;{ }^{16,19}$ and, vii) can be engineered to co-express enzymes or peptide sequences that are not natively expressed in the targeted bacteria.

Existing phage-based assays for the detection of E. coli utilize a single amplification step and detection by microscopy or cell sorting. ${ }^{18,20,21}$ The phages are pre-labeled with a fluorophore, or engineered to display a specific peptide sequence (e.g., a biotinylated peptide, ${ }^{20}$ or a tetracysteine peptide motif ${ }^{21}$ ) that is recognized by a peptide-specific fluorophore.

A point-of-access assay for bacteria that combines the simplicity of culture with the short time periods required for nucleic acid-based methods is not currently available. We describe a simple, portable, filter-based assay that can to detect fewer than 50 CFUs of E. coli in one liter of liquid in 4 hours by exploiting two different types of selective signal amplification: i) the replication of phage within live bacteria, and ii) the production of hundreds (or thousands) of colored or fluorescent molecules per second from an enzymatic reaction (Scheme 1). We use this bacteriophage-based method to identify E. coli present in samples of drinking water, milk, and orange juice.

\section{Experimental Design.}

Choice of bacterial species and liquid samples. We chose E. coli K12 (ER2378) as a model organism for the phage-based assay because: i) it is a coliform bacterium, which is a rod-shaped bacterium that is not necessarily pathogenic but may be indicative of pathogenic bacteria associated with fecal matter, and thus a target organism for EPA-approved methods; ii) it is 
engineered to not express $\beta$-galactosidase ( $\beta \mathrm{gal})$; and, iii) there is a commercially available, $\beta$ galexpressing bacteriophage.

We detected and quantified the number of CFUs of $E$. coli in drinking water, drinking water contaminated with particulates of soil ( $5 \mathrm{~g} / 100 \mathrm{~mL}$; i.e., "dirty water"), skim milk, and pulpfree orange juice. We chose to test samples of water because a significant number (15\%) of Americans, ${ }^{22,23}$ and a larger proportion of people in the developing world, obtain drinking water from private sources (e.g., a well, cistern, or stream) that are not monitored unless an outbreak of water-borne disease has occurred. We selected milk and orange juice because they are commodity foodstuffs, and require constant monitoring; there is currently no diagnostic capable of detecting the presence of bacteria in a sample of milk at the site of milk collection and processing. The collection and pooling of milk samples in the developing world, or other locales where pasteurization is not feasible, may result in a single sample of bacteria-containing milk contaminating an entire pool. ${ }^{24}$ Milk and orange juice also pose analytical challenges because they are opaque, and not compatible with assays based on a visual readout.

Choice of bacteriophage. We chose an M13 phage that co-expresses a single copy of $\beta g a l$ with each phage. A single bacterium infected by M13 phage produces an average burst size of 1000 plaque-forming units (PFUs) of phage within an hour of infection. ${ }^{25,26}$ The choice of a $\beta$ galexpressing phage is advantageous, because: i) the enzymatic turnover of $\beta g a l$ (e.g., 620 molecules $\sec ^{-1}$ at $\mathrm{pH}=7.0$ and $\left.20{ }^{\circ} \mathrm{C}\right)^{27}$ provides a second stage of amplification, and ii) the products of the enzymatic assay can be detected visually, and eliminate the need for culture steps (or a plaque assay).

Concentration and amplification of E. coli using a syringe filter. We began every assay by filtering the sample through a $0.2-\mu \mathrm{m}$ syringe filter to capture the bacteria from the sample 
(Scheme 1). These filters are available in pre-packaged sterile units, and represent a selfcontained microbiology laboratory in which the captured bacteria can be incubated and handled without fear of contamination. The filters retain the bacteria throughout multiple washing steps, which are necessary to reduce colored contaminants or excess salts from samples such as milk or orange juice that may interfere with detection, but allow for the elution and collection of newly produced phage and $\beta$ gal following incubation.

Indirect detection of $E$. coli with phage- and Bgal-based assays. The quantity of phage (or $\beta g a l)$ collected after incubation correlates with the number of viable bacteria captured on the syringe filter because bacteriophages can only replicate in a live bacterial host. To validate this correlation, we quantified the newly produced phages with a plaque assay, ${ }^{18}$ a standard microbiological assay in which the phage are introduced to solid agar containing E. coli, and plaques (regions of dead bacteria) are counted after incubation. The M13-phage-infected bacteria produce blue-colored plaques in the presence of a colorimetric substrate for $\beta$ gal: 5-bromo-4chloro-3-indolyl $\beta$-D-galactopyranoside, Xgal.

For the portable assay, we detected the captured E. coli with a solution-based assay that relies on the enzymatic activity of $\beta$ gal to produce a colorimetric or fluorescent product. A readout based on the production of a fluorescent molecule is desirable because the limit of detection of a fluorescent signal is much lower than that of a colorimetric signal, and fluorescence readings are less susceptible to interferences from colored solutions.

\section{Results and Discussion.}

Filtration of liquids through the syringe filter improves the detection of colored products.

The background absorption and/or scattering of light by opaque or colored samples make the detection of a colorimetric product difficult. We prepared samples of drinking water, orange 
juice, skim milk, and dirty water with increasing concentrations of chlorophenol red-one possible product of the $\beta$ gal assay—ranging from $4 \mu \mathrm{M}$ to $250 \mu \mathrm{M}$ (Figure 1a). The red color of chlorophenol red can be observed at a concentration of $8 \mu \mathrm{M}$ in drinking water, but is more difficult to detect in orange juice $(125 \mu \mathrm{M})$, milk $(63 \mu \mathrm{M})$, and dirty water $(16 \mu \mathrm{M})$.

Figure 1b shows samples of orange juice, milk, and dirty water before and after filtration. The increased transparency of the samples after filtration facilitates the detection of a colored or fluorescent molecule. Figure 1c compares the transmittance $(\lambda=570 \mathrm{~nm}$, the maximum absorption of chlorophenol red) of the liquid samples in Figure $1 \mathrm{~b}$ before and after filtration.

Samples of orange juice and dirty water passed easily through the $0.2-\mu \mathrm{m}$ filter, but less than $1 \mathrm{~mL}$ of skim milk clogged the filter. We found that adding a sodium hydroxide (to a final concentration of $0.4 \% \mathrm{w} / \mathrm{v}$ ) to the samples of milk greatly reduced their viscosity, and allowed them to pass through the filter. Basic solutions are known to be anti-bacterial, but short exposures are not lethal. ${ }^{28}$

Filtration of liquids through the syringe filter captures and retains bacteria. To ensure the bacteria contained in a liquid sample were captured (and retained) during filtration and several washing steps, we filtered 5-mL samples of drinking water, orange juice, skim milk, and dirty water containing $5000 \mathrm{CFUs}$ of a $\beta$ gal-expressing E. coli (NCTC 9001) and rinsed each sample with $10 \mathrm{~mL}$ of $1 \mathrm{X}$ phosphate buffered saline (1X PBS). We then centrifuged the filtrates at $14000 \mathrm{x} g$ for 10 minutes, removed the supernatant, resuspended the pellet with $1 \mathrm{~mL}$ of $1 \mathrm{X}$ PBS, and plated it on an agar plate containing Xgal. We included several positive controls (containing 5, 50, and 500 CFUs of E. coli NCTC 9001), which we suspended in $10 \mathrm{~mL}$ of $1 \mathrm{X}$ PBS, centrifuged, and plated. The positive control samples each contained blue-colored plaques, 
while the filtrates contained no plaques ( $n=3$ samples of each liquid); these results show that the syringes effectively capture bacteria from the sample, and sterilize the filtrate.

We performed a separate set of controls to determine if the viability of $E$. coli in a sample of milk decreased when exposed to sodium hydroxide $(0.4 \% \mathrm{w} / \mathrm{v})$; we found that exposures within the time required to add sodium hydroxide to a sample of milk, filter the sample, and rinse it with 1X PBS ( $\sim 15$ minutes) did not decrease the viability of 5 CFUs of $E$. coli in the sample (see Supporting Information).

\section{A culture-based readout has a limit of detection of one CFU of E. coli in one liter of}

drinking water. We determined the limit of detection of the phage-based assay with an overnight culture-based readout (i.e., a "plaque assay") for samples containing between zero and 5000 CFUs of E. coli K12. Because the plaque assay cannot distinguish between newly produced phage and excess phage remaining on the filter, we inactivated the excess phage by rinsing the filter with a solution of ferrous ammonium sulfate, ${ }^{29}$ followed by a solution of sodium citrate to chelate and remove excess ferrous ions (Scheme 1, see Supporting Information for experimental details). We incubated the syringe filters for an additional 60 minutes to allow the phages to complete their replication cycle prior passing one $\mathrm{mL}$ of $1 \mathrm{X}$ PBS through the filter, and applying the solutions to a plate of solid agar containing E. coli and Xgal (detailed procedure in Supporting Information). We counted the number of plaque-forming units (PFUs) after a 12-hour incubation, and plotted the number of PFUs as a function of CFUs of E. coli captured on the filter (Figure 2a). The number of PFUs detected in the plaque assay for large number of $E$. coli is less than expected, based on the average burst of an M13 phage of $1000{ }^{25,30}$ Early work on phage supports the relationship between phage concentration and plaque count that we observed. $^{18,31}$ 
Samples of drinking water containing a single CFU of E. coli produced $310 \pm 30$ PFUs; this value is well above the LOD, which we calculated from the background noise (20 \pm 30 PFUs) of samples containing zero E. coli. Both the LOD of the culture-based readout and the average number of PFUs observed for samples containing 5 CFUs of $E$. coli were independent of the volume of the liquid sample (Figure 2b). For a given concentration of bacteria (expressed in $\mathrm{CFU} / \mathrm{mL}$ ), however, we expect that larger sample volumes will result in more sensitive detection, due to the concentration of bacteria on the filter.

\section{Dirty water, or the presence of other species of bacteria, does not affect the phage-based}

assay. Dirty water, which is often associated with sources of water that may be contaminated, does not interfere with the assay (Figure 3a), and the number of PFUs detected from samples of drinking water and dirty water containing 50 CFUs of $E$. coli are statistically indistinguishable. We also found that the number of plaques produced from samples of drinking water containing 50 CFUs of bacteria not targeted by the M13 phage-E. coli BL21 (an $\mathrm{F}^{-}$E. coli), P. aeruginosa, and S. aureus — are statistically indistinguishable from samples containing zero bacteria (Figure 3b). Samples of drinking water containing a mixture of bacteria (e.g., 50 CFUs of E. coli K12 and 50 CFUs of E. coli BL21) produce the same number of PFUs as a sample containing only 50 CFUs of E. coli K12.

The species-specificity of a bacteriophage reduces the likelihood of false-positive readings; it is, however, important to note that a false positive is possible if the excess phage on the filter are not properly deactivated with a ferrous ion-containing solution. The need for a sterile laboratory environment (for plating and culturing the phage-containing samples) and numerous controls (to ensure that the excess phage are inactivated with ferrous ions, and excess ferrous ions are inactivated with citrate ions) makes a culture-based assay difficult to implement at the point of 
access. An ideal assay would require few experimental steps, no access to a laboratory, and produce a visual signal in less time than required for culture.

\section{A portable, visual readout-based assay has a limit of detection of 50 CFUs of E. coli in one}

liter in 4 hours. While the overlay-based assay surpasses the requirements set by the EPA for a coliform test - the ability to detect one CFU of E. coli in $100 \mathrm{~mL}$ of water in less than $24 \mathrm{~h}-\mathrm{a}$ solution-based assay, with a visual-readout, would be attractive because there are no approved point-of-access assays for bacteria that do not rely on culture of the sample.

This solution-based assay relies on the collection of the newly produced $\beta$ gal molecules, rather than newly produced phage. A readout based on $\beta$ gal eliminates the need for washing the filter with ferrous ammonium sulfate and sodium citrate because the presence of excess phage does not affect the result. Following the incubation of the sample with the phage, we treated the filter with a solution that contained lysozyme, which lysed any bacteria present on the filter and released their contents, and a substrate for $\beta$ gal (see Supporting Information). We collected the filtrate and monitored the enzymatic reaction for changes in color.

There are a number of substrates that are converted to a colored product in the presence of Bgal. ${ }^{32}$ We compared three substrates that are listed in methods already approved by the EPA: ${ }^{1} 2$ nitrophenyl $\beta$-D-galactopyranoside (ONPG), which yields 2-nitrophenol (ONP, yellow in color); chlorophenol red- $\beta$-D-galactopyranoside (CPRG), which yields chlorophenol red (CPR, red in color); and 4-methylumbelliferyl $\beta$-D-galactopyranoside (MUG), which yields 4methylumbelliferone (MU, fluorescent).

Figure 4a shows the visual limits of detection for ONP, CPR, and MU, based on the measurement of a series of standard solutions; we also measured the absorbance and fluorescence of each solution with a spectrometer to ensure that the calibration trends were linear 
(see Supporting Information). The visual limit of detection of CPR $(\sim 0.01 \mathrm{mM})$ is approximately 20 -fold lower than that of ONP $(0.2 \mathrm{mM})$, which is a more commonly used substrate for $\beta$ gal. MU was the most sensitive of the three substrates, with a visual limit of detection of $\sim 0.0003$ $\mathrm{mM}$ when excited with a handheld UV lamp or an LED emitting in the UV. LEDs are compatible with a portable assay, are easy to use, inexpensive ( $<\$ 1$ per flashlight), and require little power ( $\sim 18 \mathrm{~h}$ of continuous light, or over 10,000 samples, on a single lithium battery).

To determine the limit of detection of the solution-based assay we captured and infected between zero and 5000 CFUs of E. coli on the syringe filter, lysed the bacteria in the presence of MUG or CPRG, and collected the lysate in 1.5-mL centrifuge tubes. The fluorescent signal (of MU) in samples of water, milk, and orange juice containing 50 CFUs of E. coli was observed after 3 hours of incubation. To achieve a visible colorimetric result (using CPR) in the same period of time required $\sim 1 \times 10^{6}$ CFUs of E. coli.

Figure $4 \mathbf{b}$ shows a $0.2-\mu \mathrm{m}$ syringe filter before (left) and after (right) it was used to filter 10 $\mathrm{mL}$ of soil-contaminated water. The filtrate from the dirty water did not interfere with the visual detection of CPR or MU, whereas the visual detection of ONP was limited by the discoloration of the filtrate (Figure 4c). The presence of particulates of soil does not interfere with the visualization of MU (Figure 4d).

Phage-infected $E$. coli produce a positive result more quickly than coliform E. coli that express $\beta$ gal natively. Detection of natively expressed $\beta$ gal forms the basis of the culture-based assays for coliform bacteria approved by the EPA. The lacZ gene, which encodes $\beta$ gal, was removed from the genome of the E. coli strain (K12 ER2378) used in these proof-of-principle studies. To determine if the number (and activity) of $\beta$ gal molecules present in a sample of coliform bacteria could produce a false-positive result in the visual readout-based assay we 
compared the activity of $\beta g a l$ in samples containing $\beta$ gal-expressing E. coli (NCTC 9001, collected from urine) to our model organism, E. coli K12 ER2738.

We repeated the solution-based assay with E. coli NCTC 9001, and monitored the production of MU with a fluorescence plate reader. The time required for 50,000 CFUs of NCTC 9001 to produce a visible signal of MU was approximately 8 hours, whereas a sample of 50 CFUs of $E$. coli $\mathrm{K} 12$ produced a visual signal from MU in less than 4 hours. We conclude that the presence of endogenous $\beta$ gal will not interfere with phage-based amplification and detection. Engineering an enzymatic reporter into the phage that is not present in the target bacterium is also a plausible strategy to reduce this type of background.

\section{Conclusion.}

There is presently no convenient or cost-effective method to test samples of liquid for the presence of bacteria at a point of interest (e.g., a water source, an assembly line in a food processing plant, a container of pooled milk samples, etc). Commercially available kits rely, as do most laboratory-based assays, on the overnight culture of the sample. This paper describes an alternative assay, based on the species-specific infection of bacteria in a sample with a selfamplifying system: a bacteriophage. We have detected 50 CFUs of $E$. coli in a 1-liter sample of drinking water in less than 4 hours with a visual-based readout.

The selectivity of this assay is two-fold, and arises from the specific interactions of phage for bacteria, and of enzyme for substrate. Phages are an ideal reagent for diagnostics because, in addition to their selectivity, they can be stored dry, and can be engineered to co-express a variety of reporter enzymes that produce colored, fluorescent, or electrochemically-active species. There are a number of repositories of already sequenced phages, ${ }^{33}$ and the procedures for inserting a gene of interest into the phage genome are well-established. ${ }^{25}$ 
The sensitivity of this assay arises from two steps of amplification: i) the replication of phage, which can amplify in number by a factor of up to 1000 , and ii) the catalytic activity of a high-turnover-rate enzyme, which is co-expressed with each phage (which can produce an additional amplification of $\sim 10^{6}$ per hour for $\beta \mathrm{gal}$ ). We can increase the sensitivity of the assay by introducing a second round of phage infection and amplification — similar to the approach used to prepare overlay plates — but note that this extra step limits the utility of this assay for onsite monitoring of liquid samples. There are a number of alternatives that could increase the sensitivity of this assay while not decreasing its utility: the use of $\beta$ gal substrates with lower limits of visual detection; an electrochemical or polymerization-based assay whose product is more easily detected than a change in color; or phages engineered to co-express multiple copies of an enzyme with a high turnover rate.

\section{Supporting Information.}

A detailed procedure for the culture- and solution-based phage assays; materials and methods section; calibration curves of ONP, CPR, and MU. This material is available free of charge via the Internet at http://pubs.acs.org.

\section{Acknowledgements.}

This work was partially funded by the Bill \& Melinda Gates Foundation (grant number 51308), the National Science Foundation (CHE-1152196), and the Wyss Institute for Biologically Inspired Engineering. EJM thanks the Natural Sciences and Engineering Council of Canada for individual support (NSERC PDF). CC would like to thank the Biomaterial Research Initiative Dedicated to Gateway Experiences (NSF DMR-1005022). 


\section{References.}

(1) EPA; United States Environmental Protection Agency: Washington DC, 2002; Vol. EPA-821-R-02-020.

(2) Batt, C. A. Science 2007, 316, 1579.

(3) Heo, J.; Hua, S. Z. Sensors 2009, 9, 4483.

(4) Kaele, S. A.; Kundu, A. A.; Gosavi, S. W.; Deobagkar, D. N.; Deobagkar, D. D.; Kulkarni, S. K. Small 2006, 2, 335.

(5) Hahn, M. A.; Tabb, J. S.; Krauss, T. D. Anal. Chem. 2005, 77, 4861.

(6) Yeung, S.-W.; Lee, T. M.-H.; Cai, H.; Hsing, I.-M. Nucleic Acids Res. 2006, 34, e118.

(7) Persing, D. H. Molecular Microbiology; 2 ed.; ASM Press: Washington, DC, 2011.

(8) Diaz-Infantes, M. S.; Ruiz-Serrano, M. J.; Martinez-Sanchez, L.; Ortega, A.; Bouza, E. J. Clin. Microbiol. 2000, 38, 1988.

(9) Frahm, E.; Obst, U. J. Microbiol. Methods 2003, 52, 123.

(10) Khan, I. U. H.; Gannon, V.; Kent, R.; Koning, W.; Lapen, D. R.; Miller, J.; Neumann, N.; Phillips, R.; Robertson, W.; Topp, E.; van Bochove, E.; Edge, T. A. J. Microbiol. Methods 2007, 69, 480.

(11) Lagally, E. T.; Scherer, J. R.; Balzej, R. G.; Toriello, N. M.; Diep, B. A.; Ramchandani, M.; Sensabaugh, G. F.; Riley, L. W.; Mathies, R. A. Anal. Chem. 2004, 76, 3162.

(12) Liu, W.-T.; Zhu, L. Trends Biotechnol. 2005, 23, 174.

(13) Govindarajan, A. V.; Ramachandran, S.; Vigil, G. D.; Yager, P.; Bohringer, K. F. Lab Chip 2012, 12, 174 .

(14) Funes-Huacca, M.; Wu, A.; Szepesvari, E.; Rajendran, P.; Kwan-Wong, N.; Razgulin, A.; $\quad$ Shen, Y.; Kagira, J.; Campbell, R.; Derda, R. Lab Chip 2012, 12, 4269. 
(15) Morita, M.; Tanji, Y.; Mizoguchi, K.; Akitsu, T.; Kijima, N.; Unno, H. FEMS Microbiol. Lett. 2002, 211, 77.

(16) Wilson, M.; McNab, R.; Henderson, B. Bacterial Disease Mechanisms: An Introduction to Cellular Microbiology; Cambridge University Press: New York, New York, 2002.

(17) Goldenberg, M. I.; Abbott, C. W. J. Bact. 1965, 89, 542.

(18) Russel, M.; Lowman, H. B.; Clackson, T. In Phage Display; Oxford University Press: New York, 2004, p 1.

(19) Calendar, R. The Bacteriophages; 2nd ed.; Oxford University Press: New York, New York, 2006.

(20) Edgar, R.; McKinstry, M.; Hwang, J.; Oppenheim, A. B.; Fekete, R. A.; Giulian, G.; Merril, C.; Nagashima, K.; Adhya, S. Proc. Nat. Acad. Sci., U.S.A. 2006, 103, 4841.

(21) Wu, L.; Huang, T.; Yang, L.; Pan, J.; Zhu, S.; Yan, X. Angew. Chem., Int. Ed. 2011, 50, 5873.

(22) Factoids: Drinking water and Ground Water Statistics for 2007; United States Environmental Protection Agency: Washington, D.C., 2008.

(23) Private Drinking Water Wells; United States Environmental Protection Agency: Washington, D.C., 2011.

(24) McNeil, D. G. In New York Times New York, New York, 2011.

(25) Barbas, C. F.; Burton, D. R.; Scott, J. K.; Silverman, G. J. Phage Display: A Laboratory Manual; Cold Spring Harbor Laboratory Press: Cold Spring Harbor, New York, 2001.

(26) Derda, R.; Tang, S. K.; Whitesides, G. M. Angew. Chem., Int. Ed. 2010, 49, 5301.

(27) Lo, S.; Dugdale, M. L.; Jeerh, N.; Ku, T.; Roth, N. J.; Huber, R. E. Protein J. 2010, 29, 26. 
(28) Sharma, M.; Beuchat, L. R. Appl. Environ. Microbiol. 2004, 70, 1795.

(29) Sellak, H.; Franzini, E.; Hakim, J.; Pasquier, C. Arch. Biochem. Biophys. 1992, 15, 172.

(30) Derda, R.; Tang, S. K. Y.; Li, S. C.; Ng, S.; Matochko, W.; Jafari, M. R. Molecules 2011, $16,1776$.

(31) Ellis, E.; Delbruck, M. J. Gen. Physiol. 1939, 22, 365.

(32) Manafi, M.; Kneifel, W.; Bascomb, S. Proc. Nat. Acad. Sci., U.S.A. 1991, 55, 335.

(33) In NCBI Genome Resources; National Institutes of Health: Bethesda, MD; Vol. 2012. 


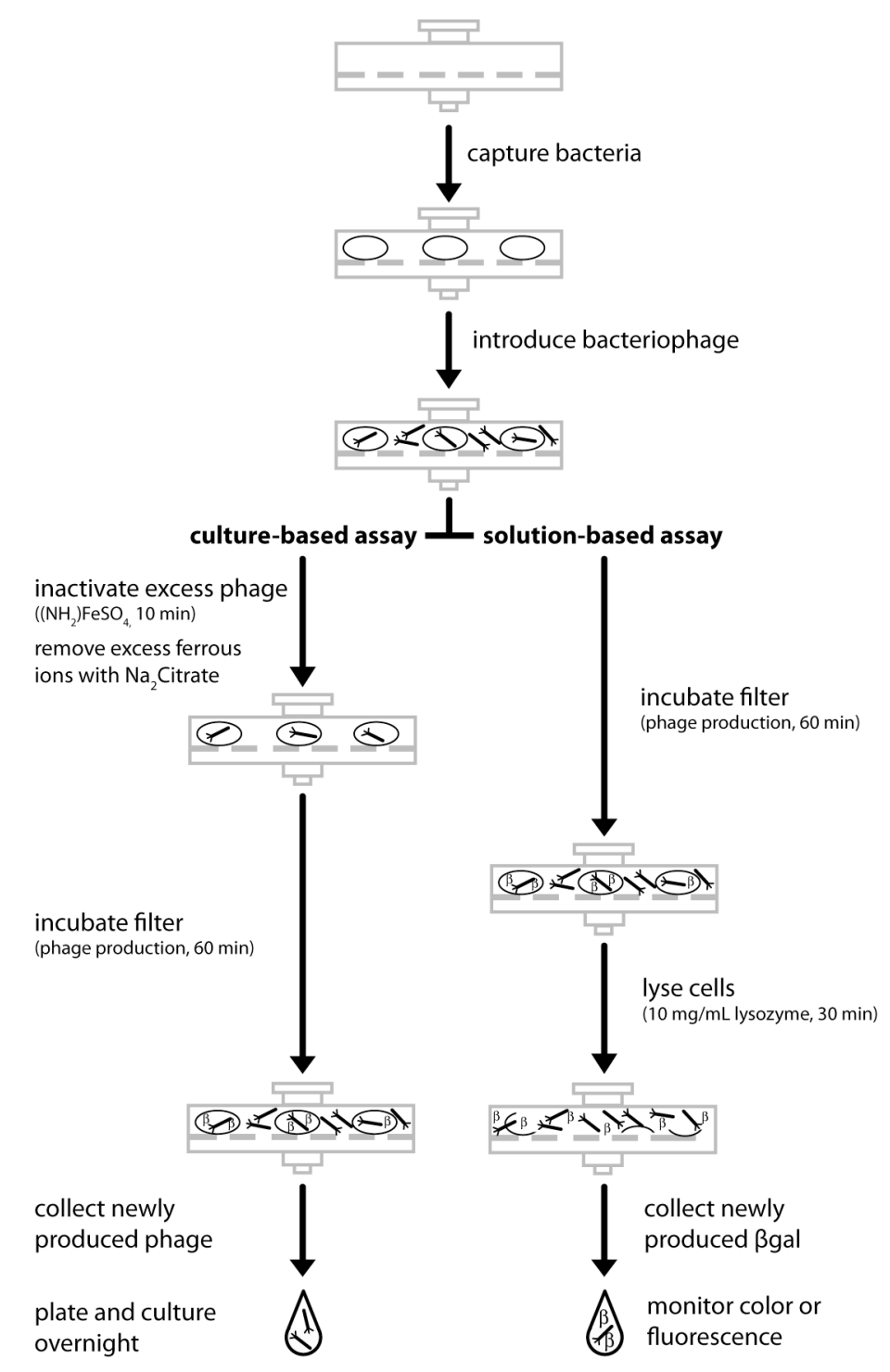

Scheme 1. Schematic of the assay based on bacteriophage amplification. Filtering an aqueous sample through a $0.2-\mu \mathrm{m}$ filter captures bacteria on the surface of the filter. A bacteriophage of interest (e.g., M13 filamentous phage, which co-expresses $\beta$ gal) is introduced to infect the bacteria. The phage replicate on the filter and co-express the enzyme of interest during an incubation period (generally 60 minutes). After incubation, the newly produced phage is quantified with a culture-based assay (an overlay plate), or the newly produced enzyme is quantified with a solution-based enzymatic assay. 
a)
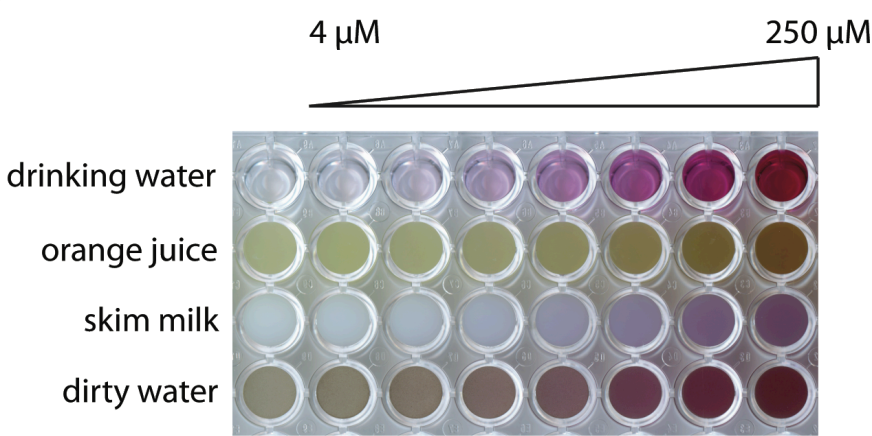

b)

orange juice

dirty water
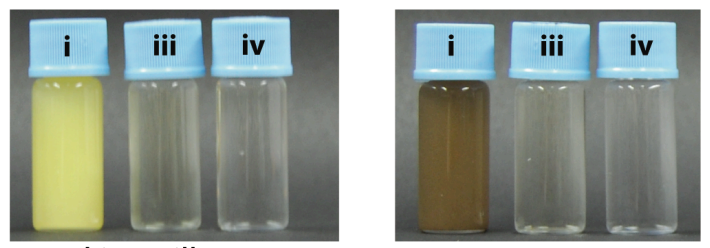

skim milk

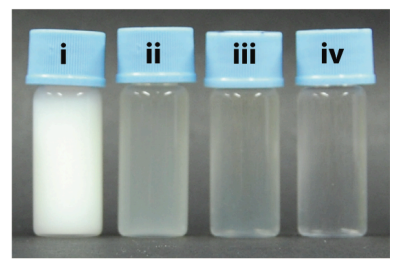

c)

\begin{tabular}{lcccc}
\hline & \multicolumn{4}{c}{ \% Transmittance $(\lambda=570 \mathrm{~nm})$} \\
sample & i & ii & iii & iv \\
\hline orange juice & 0 & & 82 & 99 \\
skim milk & 0 & 33 & 84 & 96 \\
dirty water & 0 & & 88 & 100 \\
\hline
\end{tabular}

Figure 1. a) Samples of drinking water, orange juice, skim milk, and dirty water with increasing concentrations of CPR ( $0 \mu \mathrm{M}$ left, $4 \mu \mathrm{M}$ to $250 \mu \mathrm{M}$ in 2-fold increases in concentration). b) Photographs of samples of orange juice, dirty water, and skim milk before filtration (i), after treatment with base (ii, milk only), and after filtration (iii - iv). c) Average transmittance (at 570 $\mathrm{nm}$ ) of the $\mathrm{n}=4$ samples, before and after filtration, as an indicator of opacity. 
a)

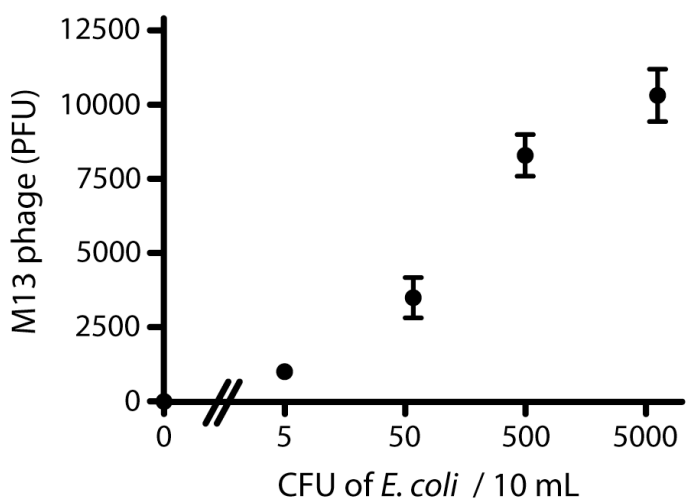

b)

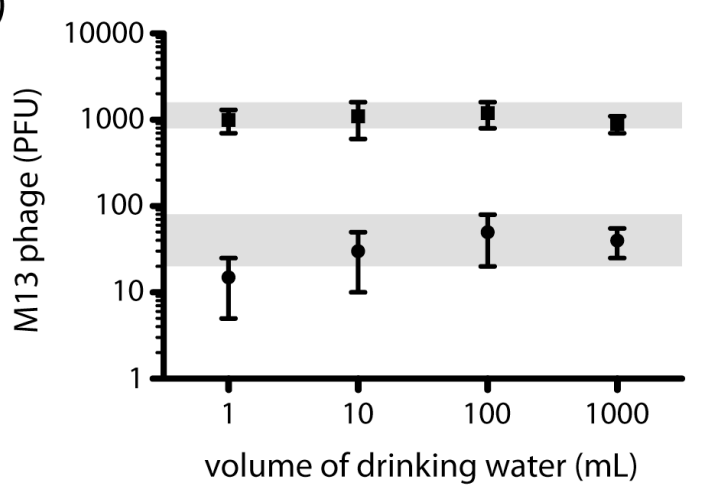

Figure 2. a) Number of PFUs of M13 phage detected with a plaque assay from 10-mL samples of drinking water containing known CFUs of E. coli. b) Number of PFUs of M13 phage detected for 1, 10, 100 and $1000 \mathrm{~mL}$ samples of drinking water containing zero CFUs of $E$. coli (bottom row) and 5 CFUs of $E$. coli (top row). The gray regions demarcate an interval within one standard deviation from the mean obtained for a sample of $100 \mathrm{~mL}$ (the volume required for EPA-approved tests for coliform bacteria in drinking water). Each point is the average of $n=9$ experiments, and the error bars represent one standard deviation from the mean. 
a)

\begin{tabular}{llll}
\hline $\begin{array}{l}\text { CFU of } \\
\text { E. coli }(\#)\end{array}$ & $\begin{array}{l}\text { soil } \\
\text { contamination }\end{array}$ & $\begin{array}{l}\text { volume of } \\
\text { sample }(\mathrm{mL})\end{array}$ & $\begin{array}{l}\text { PFU of M13 } \\
\text { phage (\#) }\end{array}$ \\
\hline 5 & no & 10 & $1100 \pm 500$ \\
5 & yes & 10 & $980 \pm 200$ \\
50 & no & 10 & $3580 \pm 200$ \\
50 & yes & 10 & $3900 \pm 600$ \\
\hline
\end{tabular}

b)

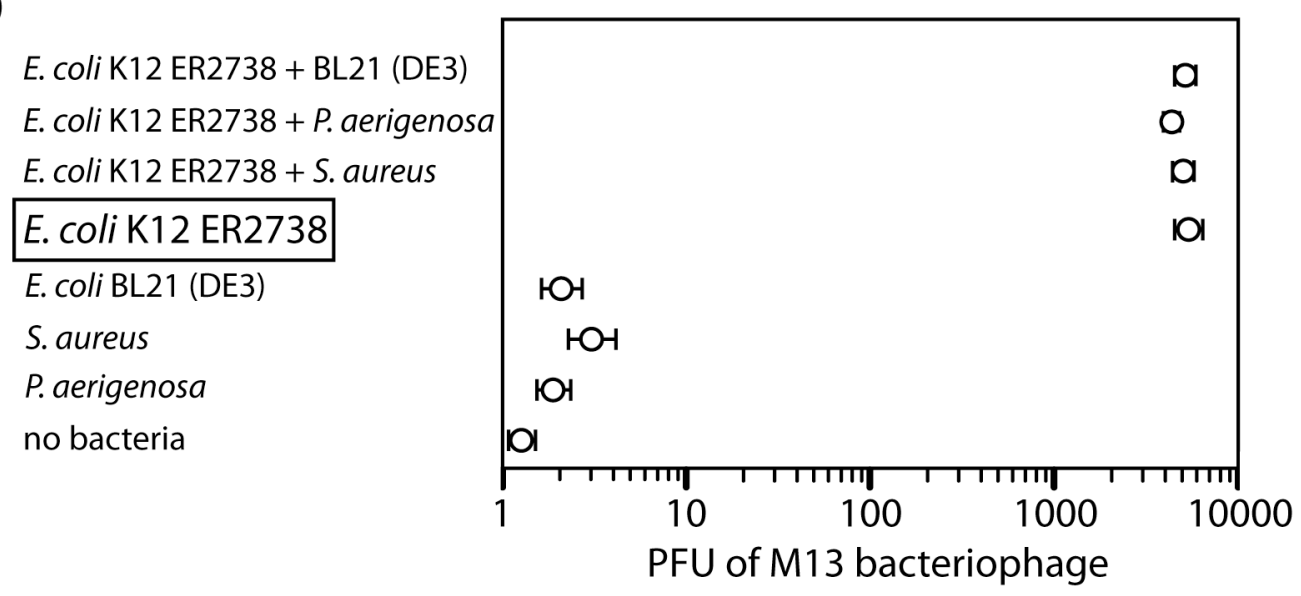

Figure 3. a) Number of PFUs of M13 phage detected with the plaque assay from samples of drinking water and dirty water (containing $5 \mathrm{~g} / 100 \mathrm{~mL}$ of soil) containing E. coli. b) Number of PFUs of M13 phage detected with a plaque assay from $10 \mathrm{~mL}$ samples of drinking water containing $50 \mathrm{CFUs}$ of the indicated bacterium. Mixtures containing two species of bacteria contained 50 CFUs of each species. Each point is the average of $n=9$ experiments, and the error bars represent one standard deviation from the mean. 


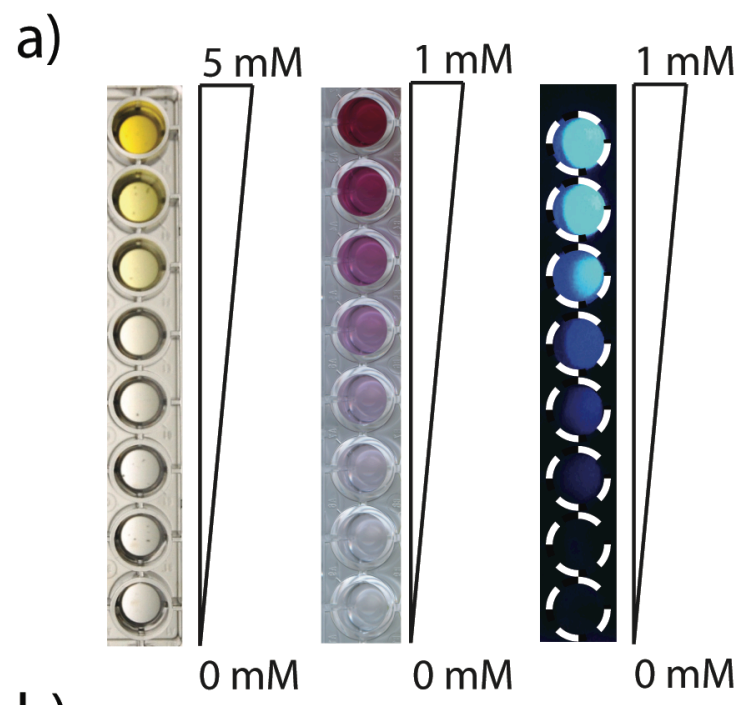

b)

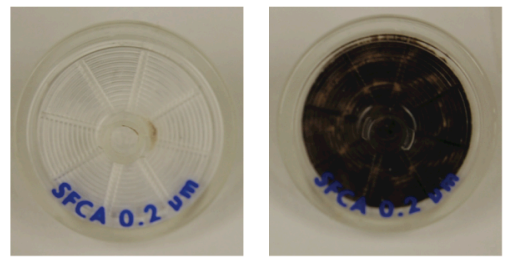

C)

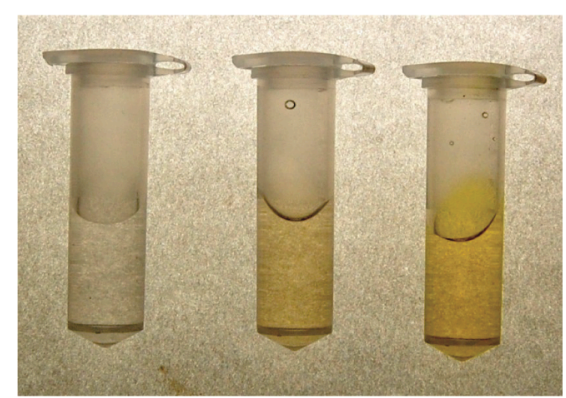

d)

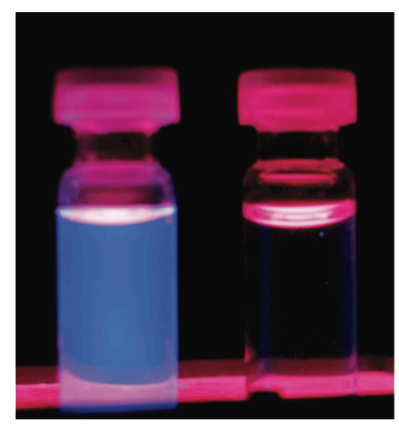

Figure 4. a) Visual detection of 2-nitrophenol (left) and chlorophenol red (middle) obtained with a flatbed scanner, or 4-methylumbelliferone (right) obtained from illuminating the samples with 
a handheld UV lamp. The concentrations of 2-nitrophenol and chlorophenol red in each row decrease by a factor of 2 (from top to bottom); the concentration of 4-methylumbelliferone in each row decreases by a factor or 10. b) Syringe filter before (left) and after (right) filtering 10 $\mathrm{mL}$ of dirty water (containing $5 \mathrm{~g}$ of soil / $100 \mathrm{~mL}$ of water). c) Three samples of liquid passed through a $0.2-\mu \mathrm{m}$ filter: (left) a sample of $1 \mathrm{X}$ PBS containing $1 \mathrm{mg} / \mathrm{mL}$ of ONPG and no bacteria; (middle) a sample of $1 \mathrm{X}$ PBS containing $1 \mathrm{mg} / \mathrm{mL}$ of ONPG and potting soil, but no bacteria; (right) a sample $1 \mathrm{X}$ PBS containing $1 \mathrm{mg} / \mathrm{mL}$ of ONPG, 5000 phage-infected E. coli, and potting soil. The coloration of the middle tube, which contained no bacteria, is due to small particulates that passed through the $0.2-\mu \mathrm{m}$ filter and is not from cleaved ONPG molecules. d) Samples of 1X PBS containing $0.1 \mathrm{mg} / \mathrm{mL}$ of MUG and potting soil. The sample on the left contained 500 phage-infected E. coli, the sample on the right contained no E. coli. 